\title{
COMMUNICATIONS
}

\section{STEREOPSIS AND DEPTH PERCEPTION AFTER TREATMENT FOR CONVERGENT SQUINT**}

\author{
BY \\ E. J. NAYLOR, T. E. SHANNON, AND A. STANWORTH \\ Department of Ophthalmology, University of Manchester
}

THIS survey arose out of a paper by one of us (Stanworth, 1949) reporting the improvement of binocular vision after squint operations in patients in whom restoration of binocular vision was not expected, and analysing the factors which influenced the results. Since that date, the long-term results of treatment of concomitant strabismus in terms of binocular function has been the subject of discussion at the Oxford Congress of the Faculty of Ophthalmologists in 1952. Cashell (1952) found that of the patients discharged in 1949 who were non-binocular as determined by the cover test, 18 per cent. had improved in binocular vision by the time they were reexamined in 1952; this suggested to him that in any series of cases binocular function will improve with the passage of time provided the visual axes are rendered approximately parallel. Although the age at which operation was performed "gave similar curves for both binocular and non-binocular results", he felt that early operation was important. On the other hand, Douglas (1952a) found that, in his series, the age at operation had little or no influence on the results; in both series the operation was done most commonly between the ages of 5 and 10 years. Whittington (1952) was in favour of delaying operation in a patient with complete alternation until fusion could be trained; Lyle (1952) found that the results of early operation were better than those when operations were delayed, but he did not state whether or not the age at onset was allowed for; on general principles, he preferred early operation, within one year of onset. Nordlöw (1956) found that the results in patients operated on within 4 years of onset were significantly better than in patients treated without operation, but he did not compare his results with those obtained by operation at a later date. On the other hand, Parfonry and Polliot (1953) preferred to delay operation until puberty. Most authors stress the importance of the age at onset.

The assessment of the final functional result is usually made on the basis of the cover test and examination on the synoptophore. Douglas (1952b) 
also used a simple test for depth perception, involving striking a pin with a small hammer, and found no difference between a group of squint patients with binocular single vision, a group of squint patients without binocular single vision but with "cosmetically straight" eyes and a group of normal controls. Lyle and Foley (1955) used the Livingston rotating depth perception apparatus, and showed that the average error and time for adjustment was much smaller for patients with binocular single vision than for those with either "subnormal" or "defective" binocular vision, but the variations within each group and the performance of normal controls were not given. These authors felt, as did Burian (1947) and Stanworth (1952), that the presence of peripheral fusion was of significance in the patients with "subnormal" binocular vision.

\section{Present Investigation}

In the present series an analysis of the end result in patients without fusion before operation was carried out on 151 cases; the analysis was also extended to include 112 patients with fusion before operation and twenty patients discharged as cured from the orthoptic department without operation. The final value of the stereopsis attained was assessed by depth perception tests and by the cover test, and these findings were also correlated with the amplitude of fusion found on the synoptophore.

Clinical Material.-In order to vary the time since operation, those patients were included who had had an operation between 1943 and 1953. As the presence of a large waiting list meant that the patients operated on already formed a highly selected group, it was not possible to make a random selection of all patients with convergent squint, but an effort was made by a random selection of routine notes from the files, and by distributing the cases between different surgeons and years of operations, to form a reasonable sample of the whole. Patients who had been included in the previous analysis by Stanworth (1949) were excluded.

The patients treated by operation comprised 105 males and 168 females. They were aged from 7 to 30 years; the angle of squint before operation was from $+8^{\circ}$ to $+50^{\circ}$; the age at operation was between 5 and 24 years; the interval from onset to operation was between 6 months and 19 years. The patients treated without operation comprised eight males and twelve females, aged from 7 to 21 years.

Depth Perception Tests.-After a routine clinical and orthoptic examination, 69 of the 85 patients with post-operative stereopsis were given depth perception tests; two of these tests were used routinely and during the later part of the study a third test was added. These tests were also carried out on the twenty patients treated without operation, on eleven normal subjects aged from 7 years to 19 years, and on twelve patients without post-operative stereopsis, seven of whom showed some evidence of fusion.

The first two tests were both carried out at a distance of $5 \mathrm{~m}$. The patient, wearing glasses if required, had his head supported by a chin and forehead rest.

In the first apparatus (drop test), the patient fixed the centre of a horizontal 
black cord across the width of an evenly illuminated cubic white box about two feet wide. With all room lights extinguished, thirty small black spherical beads were dropped, $15 \mathrm{~cm}$. in front of or behind the cord in a pre-determined random order and the patient was required to state the position of each bead relative to the cord by saying "front" or "back".

In the second apparatus (rod test), a pair of dull black vertical rods $3 \mathrm{~mm}$. in diameter were separated laterally by a space of $6 \mathrm{~cm}$. and set against an evenly illuminated white background in a cubic box. One rod was set, again in random order, $5 \mathrm{~cm}$. in front of or behind the second. Suitable screens prevented the patient from seeing the top or bottom of the rods. In each of thirty trials, the rods were seen by the patient for two seconds, and he was required to state the position of the left-hand rod relative to the right-hand rod.

The binocular parallax involved in these two tests was about 75 seconds for the drop test, and about 25 seconds for the rod test; the minimum perceptible by normal adult observers may be taken as 10 seconds (Ogle, 1950), or even as low as 2 seconds (Hirsch and Weymouth, 1948).

The third test was identical with the rod test except that it was carried out at a distance of $50 \mathrm{~cm}$., and the movable rod was only $6 \mathrm{~mm}$. in front or behind the other, giving a binocular parallax of 300 seconds.

The use of the three tests together, therefore, gave tests of different sensitivities and simultaneously allowed for correlation with both distance and near cover tests, but did not imply any direct comparison of the stereoscopic acuities for distance and near.

In all these tests the procedure was explained to the patient, and he was allowed one practice trial. His responses were limited to saying "front" and "back", a forced-choice type of response found by Blackwell (1952) to give the most reliable results in psychophysical experiments. Despite the precautions to avoid the presence of uniocular clues it was found that the number of correct answers when normal subjects were tested uniocularly was slightly more than the 50 per cent. correct that would be expected by chance, especially in the rod test at $50 \mathrm{~cm}$., but it was calculated that a score of 24 or more on either distance test, or of 25 on the near test, would arise by chance only one in 100 times. These figures were used as the basis for the classification of the degree of depth perception, to be described later.

\section{Results}

Stereopsis.-On the basis of tests previously carried out in the orthoptic department, the patients treated by operation were divided into two groups.

(A) Patients without fusion immediately before operation

(i) 115 patients without binocular vision ("No B.V."). When these tests were carried out, "No B.V." meant that simple simultaneous perception slides were not seen simultaneously, or were seen only when widely separated.

(ii) 36 patients with simultaneous perception only ("S.P."); i.e., the slides could be superimposed at the subjective angle.

The analysis was originally made for these two categories separately, but since patients in the "No B.V." category may on occasion have shown evidence of simultaneous perception, the results are given in this paper for the group as a whole except where additional useful information could be obtained from separate consideration. 
The results are summarized in the upper portion of Table $I$, the corresponding figures obtained by Stanworth (1949) being shown in parentheses. In each series the chances of improvement to fusion or better are about three times as great in patients with "S.P." as in those with "No B.V.". The proportion of patients attaining fusion or better does not differ significantly in the two series, but a considerably smaller proportion attained stereopsis in the present series. This may probably be explained by differences in the criteria employed. In the present series the post-operative classification depends on the binocular vision found at one special examination, but patients were classified as having stereopsis by Stanworth (1949) if this had been demonstrated on any occasion after operation, and the stereoscopic slides employed may on some occasions have tested paramacular stereopsis only.

TABLE I

CHANGES IN BINOCULAR VISION AFTER OPERATIONS FOR CONVERGENT SQUINT

\begin{tabular}{|c|c|c|c|c|c|c|}
\hline \multirow{2}{*}{\multicolumn{2}{|c|}{ Group }} & \multirow{3}{*}{$\begin{array}{c}\begin{array}{c}\text { Binocular Vision } \\
\text { before Operation }\end{array} \\
\text { No B.V. }\end{array}$} & \multirow{2}{*}{$\begin{array}{l}\text { Number } \\
\text { of Cases }\end{array}$} & \multicolumn{3}{|c|}{ Binocular Vision after Operation } \\
\hline & & & & \multirow{2}{*}{$\frac{\text { No B.V. or S.P. }}{97(51)}$} & \multirow{2}{*}{$\frac{\text { Fusion }}{13(2)}$} & \multirow{2}{*}{$\frac{\text { Stereopsis }}{5(7)}$} \\
\hline A & (i) & & $115(60)^{*}$ & & & \\
\hline & (ii) & S.P. only & $36(40)$ & $21(23)$ & $9(4)$ & $6(13)$ \\
\hline \multicolumn{2}{|c|}{ Total } & & $151(100)$ & $118(74)$ & $22(6)$ & $11(20)$ \\
\hline \multirow[t]{2}{*}{ B } & (i) & Fusion & 58 & 1 & 27 & 30 \\
\hline & (ii) & Stereopsis & 54 & 1 & 9 & 44 \\
\hline \multicolumn{2}{|c|}{ Total } & & 112 & 2 & 36 & 74 \\
\hline
\end{tabular}

* The figures in parentheses show results obtained by Stanworth (1949).

The factors which were considered to have a possible influence on post-operative binocular vision are shown in Table II. In Group A, the age at onset is a significant factor, the later the onset, the better the prognosis; 23 of the 26 patients in whom onset occurred later than at 2 years of age, and eight of the seventeen in whom onset occurred later than at 4 years, showed improvement in binocular vision to fusion or stereopsis.

The post-operative angle was also significant, but this may have been the result, rather than the cause, of improved binocular vision (Stanworth, 1949).

In the present series, a vertical deviation of 3 or more prism dioptres was an unfavourable factor; of 39 such patients only four developed weak fusion (amplitude less than $10^{\circ}$ ); none of the five patients with post-operative incomitance showed any improvement in binocular vision. The significance of postoperative orthoptic treatment may well be due to selection for treatment of patients who have already shown evidence of improvement in binocular vision.

Table II shows that three factors found to be significant by Stanworth (1949) were not found in the present series to influence the total number attaining fusion; a pre-operative difference in visual acuity between the two eyes of more than two Snellen lines, or an anisometropia of 2 dioptres or more may nevertheless have had some effect in preventing the development of stereopsis, in that nine such patients developed fusion or better, but of these seven had only weak fusion. 
TABLE II

POSSIBLE FACTORS INFLUENCING BINOCULAR VISION AFTER OPERATION

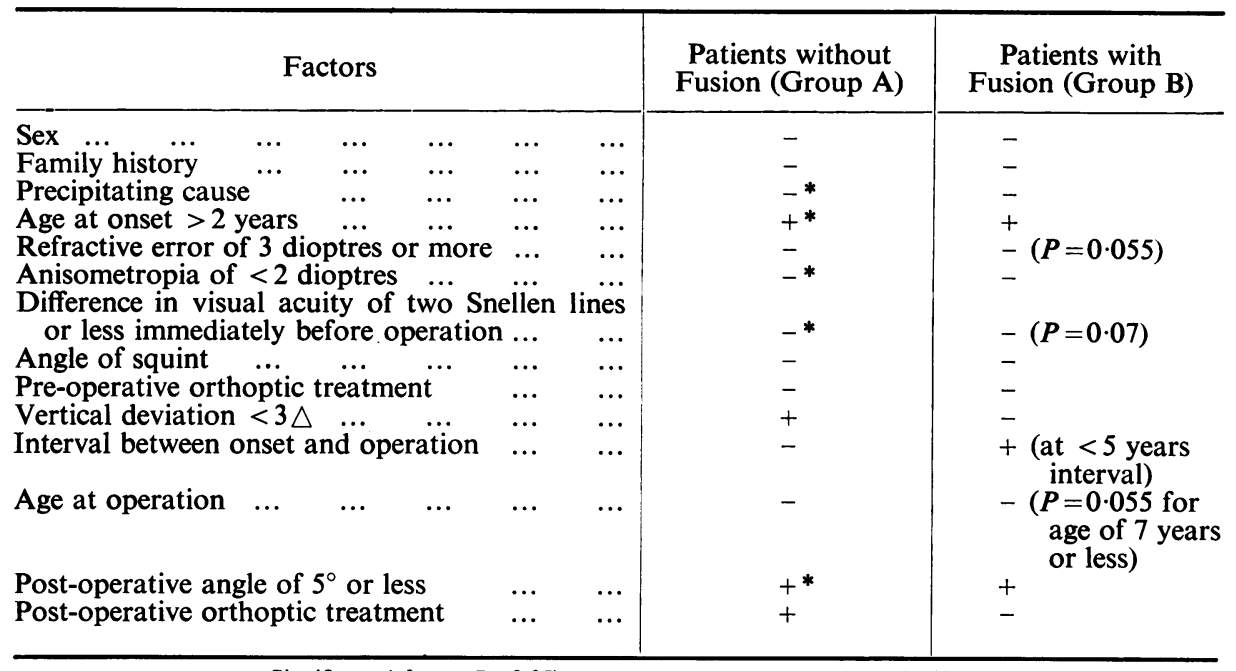

$+=$ Significant $\left(x^{2}\right.$ test, $\left.P \leqslant 0 \cdot 05\right)$.

*Found to be significant by Stanworth (1949).

Since it is not possible to assess binocular vision on the synoptophore in very young children, this series does not include any patients operated on before the age of 5 years, or within 2 years of the onset of the squint. The finding that these two factors were not significant in this group does not therefore have any relevance to the question of early operation.

Fifty patients had had pre-operative orthoptic treatment for four or more sessions without apparent benefit; nine of these attained fusion, and five showed stereopsis, but this proportion is no greater than that in the remaining patients who had not had orthoptic treatment.

Though more than half of the patients were not examined by us until more than 12 months after operation, it was possible to determine from their routine notes the stage at which improvement in binocular vision took place. Of the 33 patients involved, eighteen showed improvement within 6 months, eight within 12 months, and two within 18 months; in the remaining five patients, no orthoptic examination had been made within 2 years of operation. It appears then that improvement is normally seen in the first 6 months, and almost always within 12 months. Evidence of weak fusion at any time before operation was not of prognostic value, since some patients with such evidence failed to show improvement in binocular vision, and conversely some patients without such evidence improved after operation. Similarly, some patients classified on the basis of their immediate preoperative test as having no binocular vision occasionally showed evidence of simultaneous perception, but this was of no help in prognosis.

(B) Patients with fusion immediately before operation

(i) 58 patients with fusion but no stereopsis:

(a) Thirteen with amplitude of fusion of less than $10^{\circ}$ (weak fusion).

(b) 45 with amplitude of fusion of $10^{\circ}$ or more (strong fusion).

(ii) 54 patients with stereopsis. 
The post-operative binocular vision is shown in the lower part of Table I. The analysis was again carried out on each category separately, but since the results were virtually identical in the patients with weak and strong fusion, and since patients in the fusion category may have shown occasional evidence of stereopsis at some time, though not immediately, before operation, the further results are presented for the group as a whole.

The influence of various factors on the post-operative binocular vision is again shown in Table II. The age at onset, which was in general greater than in Group A, was again of significance; only eleven of the 25 patients in whom onset occurred before the age of 2 years had stereopsis after operation, compared with 63 of the 87 patients in whom onset occurred later than this. A small postoperative angle, and a short interval between the onset of squint and the operation were also significant factors; the latter is obviously dependent to some extent on the age at onset, in that, in a series with pre-operative synoptophore readings, any child with an early onset of squint must have waited a considerable time before operation, and, conversely, a child with a squint of late onset would tend to have an operation within a shorter time. Nevertheless, for each age at onset a higher proportion of post-operative stereopsis was consistently found in patients operated on within 5 years of onset. On the other hand, in patients whose operation was performed more than 5 years after the onset of squint, the age at onset had no significant influence on the final degree of binocular vision.

There was a marked tendency for patients operated on at the age of 7 years or less to show better results, but this was not quite statistically significant $(P=0 \cdot 055)$; of the sixteen patients concerned, only two failed to show stereopsis after operation and in both the age at onset was 2 years or less, and the interval between onse and operation was 5 years.

There was a tendency for the results to be better in patients with not more than two Snellen lines difference in pre-operative visual acuity $(P=0 \cdot 07)$. There was a marked tendency for the results to be better in patients with an average refractive error of 3 dioptres or more $(P=0.055)$. There was no suggestion that a difference in refractive error between the two eyes was a bar to stereopsis.

Post-operative treatment had been given to a greater proportion of patients who did not have stereopsis after operation; this is obviously due to the selection of such patients for treatment and is irrelevant to the question of the value of such treatment.

Of the thirty patients with pre-operative fusion who developed stereopsis, twenty had developed stereopsis within 6 months of operation, and a further four within 12 months.

Depth Perception.-The results of these tests are shown in Table III (opposite), which shows that better results were attained in the rod test at $5 \mathrm{~m}$. than in the drop test, even though the binocular parallax involved in the latter was three times greater than that in the former. This may be because the bead in the drop test was visible for only about one-tenth of a second, whereas the rods were visible for 2 seconds. Owing to the high binocular parallax the highest number of correct answers was given to the rod test at $50 \mathrm{~cm}$. 
TABLE III

RESULTS OF DEPTH PERCEPTION TESTS

\begin{tabular}{|c|c|c|c|c|c|c|}
\hline & \multicolumn{2}{|c|}{$\begin{array}{c}\text { Depth Perception } \\
\text { Tests }\end{array}$} & $\begin{array}{l}\text { Normal } \\
\text { Subjects }\end{array}$ & $\begin{array}{l}\text { Stereopsis } \\
\text { after } \\
\text { Operation }\end{array}$ & $\begin{array}{l}\text { Stereopsis } \\
\text { without } \\
\text { Operation }\end{array}$ & $\begin{array}{c}\text { Patients } \\
\text { without } \\
\text { Stereopsis }\end{array}$ \\
\hline \multirow[b]{2}{*}{ Drop Test } & \multicolumn{2}{|r|}{ Patients Tested } & 11 & 68 & 20 & 12 \\
\hline & & Correct Answers: $\begin{array}{r}28-30 \\
24-27 \\
<24\end{array}$ & $\begin{array}{l}2 \\
4 \\
5\end{array}$ & $\begin{array}{r}1 \\
1 \\
66\end{array}$ & $\begin{array}{r}1 \\
1 \\
18\end{array}$ & $\begin{array}{r}0 \\
0 \\
12\end{array}$ \\
\hline \multirow{4}{*}{ Rod Test } & \multirow[b]{2}{*}{$5 \mathrm{~m}}$. & Patients Tested & 11 & 69 & 20 & 12 \\
\hline & & Correct Answers: $\begin{aligned} & 28-30 \\
& 24-27 \\
&<24\end{aligned}$ & $\begin{array}{l}9 \\
1 \\
1\end{array}$ & $\begin{array}{r}6 \\
7 \\
56\end{array}$ & $\begin{array}{r}4 \\
2 \\
14\end{array}$ & $\begin{array}{r}0 \\
0 \\
12\end{array}$ \\
\hline & \multirow[b]{2}{*}{$50 \mathrm{~cm}$. } & Patients Tested & 1 & 45 & 18 & 2 \\
\hline & & Correct Answers: $\begin{array}{r}28-30 \\
25-27 \\
<25\end{array}$ & $\begin{array}{l}1 \\
0 \\
0\end{array}$ & $\begin{array}{r}26 \\
7 \\
12\end{array}$ & $\begin{array}{l}9 \\
2 \\
7\end{array}$ & $\begin{array}{l}0 \\
0 \\
2\end{array}$ \\
\hline
\end{tabular}

The grade of depth perception present was classified as follows:

Grade 1. 28 or more correct answers to either drop test or rod test at $5 \mathrm{~m}$.

Grade 2. 24 to 27 correct answers to either drop test or rod test at $5 \mathrm{~m}$.

Grade 3. Less than Grade 2, but 28 or more correct answers to rod test at $50 \mathrm{~cm}$.

Grade 4. 25 to 27 correct answers to rod test at $50 \mathrm{~cm}$.

Grade 5. Less than 25 correct answers to rod test at $50 \mathrm{~cm}$.

In subjects who were not given a rod test at $50 \mathrm{~cm}$., it was not possible to make a distinction between Grades 3, 4, and 5 .

The results are shown in Table IV. The only subject in the control series

TABLE IV

GRADES OF DEPTH PERCEPTION

\begin{tabular}{|c|c|c|c|c|}
\hline Grade & $\begin{array}{l}\text { Normal } \\
\text { Subjects }\end{array}$ & $\begin{array}{l}\text { Stereopsis } \\
\text { after } \\
\text { Operation }\end{array}$ & $\begin{array}{l}\text { Stereopsis } \\
\text { without } \\
\text { Operation }\end{array}$ & $\begin{array}{c}\text { Patients } \\
\text { without } \\
\text { Stereopsis }\end{array}$ \\
\hline 1 & 9 & 7 & 4 & 0 \\
\hline 2 & 1 & 6 & 3 & 0 \\
\hline $\begin{array}{r}3 \\
4 \\
5 \\
\text { No further test }\end{array}$ & $\begin{array}{l}1 \\
0 \\
0 \\
0\end{array}$ & $\begin{array}{r}15 \\
7 \\
12 \\
22\end{array}$ & $\begin{array}{l}3 \\
2 \\
7 \\
1\end{array}$ & $\begin{array}{r}0 \\
0 \\
2 \\
10\end{array}$ \\
\hline Total 3 or worse & 1 & 56 & 13 & 12 \\
\hline Total & 11 & 69 & 20 & 12 \\
\hline
\end{tabular}


who failed to achieve at least Grade 2 was a child aged 9 years with uniocular myopia resulting in a visual acuity of only $6 / 36$ in that eye; this may explain her relatively poor performance at $5 \mathrm{~m}$. In contrast to the 80 per cent. of control patients who achieved Grade 1, only 10 per cent. of patients with post-operative stereopsis and 20 per cent. of patients discharged without operation attained this Grade. None of the patients without stereopsis showed any evidence of depth perception in these tests.

Tests for correlation were carried out between the degree of depth perception and the factors which might influence the post-operative binocular vision ( $\chi^{2}$ test, $P \leq 0.05$ ). The only significant correlation was between Grade 1 depth perception and an interval between onset of squint and operation of less than 5 years. This correlation was still just significant if only Group B patients (i.e. those with pre-operative fusion or stereopsis) were considered, and was still present when patients with pre-operative fusion were considered separately from those with pre-operative stereopsis; it was not therefore due to cases of apparently good prognosis (i.e. stereopsis before operation) having an earlier operation. There was a slight tendency, not statistically significant, for there to be a greater proportion with Grade 5 depth perception in patients in Group $A(P=0.14)$ and in patients whose age at onset was less than 3 years $(P=0 \cdot 10)$; these two factors are obviously inter-related. No patient with a post-operative angle of more than $5^{\circ}$, or a pre-operative vertical deviation of 3 prism dioptres or more, had bette than Grade 3 depth perception.

The distribution of the ages at onset of the patients discharged without operation was almost identical with that of the patients in Group B who developed stereopsis; none of the three patients in whom onset occurred before the age of 2 years and only one of the eight in whom onset occurred before the age of 3 years had better than Grade 3 depth perception.

Fusion Amplitude.-Of the patients with post-operative stereopsis, 54 had an amplitude of fusion of $10^{\circ}$ or more, and 31 had less than $10^{\circ}$. There was a statistically significant correlation of a large fusion amplitude with an interval between onset and operation of less than 5 years, but there was no obvious correlation with the actual age at onset. A significantly higher proportion of patients with a large fusion amplitude had Grade 3 depth perception or better.

Cover Test.-Further analysis was carried out on similar lines of the results in patients tested for depth perception, using the results of the cover test for near and distance (Table V, opposite). The patients discharged as cured without operation showed better results in the cover test than those with stereopsis after operation. In the 69 patients with postoperative stereopsis, there was a significant correlation between the presence of a manifest squint and an interval between onset and operation of 5 years or more; this was even more marked if Group B patients only were 
TABLE V

RESULTS OF COVER TEST ON SUBJECTS WITH STEREOPSIS

\begin{tabular}{c|l|c|c|c|c}
\hline Type of Subject & Cover Test & No Movement & Heterophoria & $\begin{array}{c}\text { Fixation } \\
\text { Disparity }\end{array}$ & $\begin{array}{c}\text { Manifest } \\
\text { Squint }\end{array}$ \\
\hline $\begin{array}{c}\text { Post-operative } \\
\begin{array}{c}\text { Stereopsis } \\
\text { (69 patients) }\end{array}\end{array}$ & Distance & 29 & 16 & 4 & 20 \\
\hline $\begin{array}{c}\text { Stereopsis without } \\
\begin{array}{c}\text { Operation } \\
\text { (20 patients) }\end{array}\end{array}$ & Distance & 15 & 1 & 5 & 16 \\
\cline { 2 - 6 } & Near & 12 & 6 & 1 & 1 \\
\hline
\end{tabular}

considered. There was no obvious correlation with the age at onset. There was also a significant correlation of each cover test with the pre-operative difference in visual acuity. There was a significant correlation between the near cover test and the fusion amplitude.

On the basis of the cover test, it is possible to classify these 69 patients into two categories:

(1) 42 with binocular single vision; i.e. straight for near and distance, or showing heterophoria with good recovery. These patients correspond to those described as "binocular result" (Cashell, 1952) or "functionally satisfactory" (Lyle and Foley, 1955).

(2) 27 with a manifest deviation or fixation disparity for either near or distance, i.e. "subnormal binocular vision" (Lyle and Foley, 1955).

Table VI shows the grades of depth perception of patients in these categories; only 7 per cent. of those with subnormal binocular vision attained Grade 1 or 2 , and only 26 per cent. of those with a satisfactory cover test. Functionally satisfactory patients were just as numerous in Group A as in Group B. Seven of the

TABLE VI

GRADES OF DEPTH PERCEPTION, PATIENTS CLASSIFIED BY COVER TEST

\begin{tabular}{|c|c|c|c|c|}
\hline \multirow{2}{*}{ Grade } & \multicolumn{2}{|c|}{ Stereopsis after Operation } & \multicolumn{2}{|c|}{ Stereopsis without Operation } \\
\hline & $\begin{array}{l}\text { Functionally } \\
\text { Satisfactory }\end{array}$ & $\begin{array}{l}\text { Sub-Normal } \\
\text { Binocular } \\
\text { Vision }\end{array}$ & $\begin{array}{l}\text { Functionally } \\
\text { Satisfactory }\end{array}$ & $\begin{array}{l}\text { Sub-Normal } \\
\text { Binocular } \\
\text { Vision }\end{array}$ \\
\hline 1 & 7 & 0 & 4 & 0 \\
\hline 2 & 4 & 2 & 3 & 0 \\
\hline $\begin{array}{r}3 \\
4 \\
5 \\
\text { No further test }\end{array}$ & $\begin{array}{r}11 \\
4 \\
5 \\
11\end{array}$ & $\begin{array}{r}4 \\
3 \\
7 \\
11\end{array}$ & $\begin{array}{l}3 \\
1 \\
2 \\
1\end{array}$ & $\begin{array}{l}1 \\
0 \\
5 \\
0\end{array}$ \\
\hline Total 3 or worse & 31 & 25 & 7 & 6 \\
\hline Total & 42 & 27 & 14 & 6 \\
\hline
\end{tabular}


fourteen functionally satisfactory patients discharged as cured without operation achieved Grades 1 or 2, whereas none of the six with subnormal binocular vision did so.

\section{Discussion}

The main interest in this study lies in the answers to five questions:

(1) What factors determine the presence of stereopsis after operation?-It is evident that the greater the degree of binocular vision before operation, the greater it is likely to be after operation, and one factor which is well known to determine the pre-operative binocular vision is the age at onset; our findings confirm this. In addition, we found that the age at onset was an important factor in determining the presence of stereopsis after operation irrespective of the presence or absence of pre-operative fusion. In patients with pre-operative fusion (Group B) an additional independent factor was the interval between onset and operation; no data was available for the influence of this factor on patients without pre-operative fusion (Group A). The presence of vertical deviation in patients in Group A, of a low refractive error in Group B, and of partial amblyopia in both groups, may have had an adverse influence on the final results, but these factors are not of much prognostic value.

(2) What degree of depth perception is present in patients who show stereopsis on the synoptophore?-The striking result is the very poor depth perception attained, both by the post-operative patients and by those discharged as cured without operation. Only one of every ten patients with post-operative stereopsis, and two of every ten patients discharged as cured without operation, had depth perception approaching normal. Even on the easiest test employed, about three patients in ten showed no evidence of depth perception.

(3) What factors determine the presence of good depth perception in patients with post-operative stereopsis?-The outstanding factor appeared to be the interval between onset and operation; these results suggest that operation should not be postponed until the presence of fusion can be ascertained. Patients who did not have fusion pre-operatively did not do quite so well in the depth perception tests, which detracts slightly from the importance of the development of stereopsis in this group.

(4) Do clinical tests give a guide to the degree of depth perception present? None of the twelve patients who failed to show stereopsis on the synoptophore showed any evidence of depth perception. Of those with stereopsis, the best depth perception was found in patients with a functionally satisfactory cover test, though even so, only one in every six of the post-operative patients, and less than two in every six of those discharged as cured without operation, had depth perception approaching normal; in each case about one in six showed no evidence of depth perception in the easiest test employed.

Though there was a good correlation with depth perception, the fusion amplitude did not give any better idea of the depth perception present than that given by the cover test alone.

(5) Of what value is their binocular vision to those patients who show stereopsis on the synoptophore but have sub-normal depth perception?-It is well known (Weymouth and Hirsch, 1947) that the superiority of binocular over uniocular 
depth perception is most marked at short distances; for a normal observer, binocular vision gives no better depth perception than uniocular vision beyond a distance of about $1,000 \mathrm{~m}$., but at $2 \mathrm{~m}$. its superiority is ten-fold. If an observer, as might well have been the case with many of our patients, had binocular depth perception of one-tenth or less of normal, it would be expected therefore to be of little value to him at any distance beyond $2 \mathrm{~m}$. Such patients would make use of their binocular depth perception for close work only, and even so it would be of much less value to them than to normal persons.

Though routine tests for peripheral or paramacular fusion were not carried out on these patients, our experience with such tests (Stanworth 1952, 1955) suggests that they had peripheral fusion and that this may have been a factor in maintaining the visual axes parallel in patients who were making no appreciable use of binocular depth perception.

\section{Summary}

263 patients were examined at varying intervals after operation for convergent squint, and depth perception tests were carried out on 69 patients with stereopsis, twelve patients without stereopsis, and twenty patients who were discharged as cured from the orthoptic department without operation. The factors which determine the presence of post-operative stereopsis and good depth perception, and the value to such patients of their binocular vision, are discussed.

We wish to thank the staff of the Orthoptic Department for carrying out the orthoptic investigations, and the surgeons at the Royal Eye Hospital, Manchester, for allowing us to see their patients.

\section{REFERENCES}

Blackwell, H. R. (1952). J. opt. Soc. Amer., 42, 606.

Burian, H. M. (1947). Amer. J. Ophthal., 30, 1005.

Cashell, G. T. W. (1952). Trans. ophthal. Soc. U.K., 72, 367.

Douglas, A. A. (1952a). British Journal of Ophthalmology, 36, 169. (1952b). Trans. ophthal. Soc. U.K., 72, 383.

Hirsch, M. J., and Weymouth, F. W. (1947). J. Aviat. Med., 18, 594.

- (1948). Arch. Ophthal. (Chicago), 39, 210.

LYLE, T. K. (1952). Trans. ophthal. Soc. U.K., 72, 403. and Foley, J. (1955). British Journal of Ophthalmology, 39, 474.

Nordlöw, W. (1956). A.M.A. Arch. Ophthal., 55, 87.

OGLE, K. N. (1950). " Researches in Binocular Vision", p. 137. Saunders, Philadelphia.

Parfonry, J., and Polliot, L. (1953). "Le traitement chirurgical du strabisme concomitant" Société d'ophtalmologie de Paris: Rapport Annuel (Supplément au Bulletin d'Ophtalmologie de Paris, No. 4.).

Stanworth, A. (1949). British Journal of Ophthalmology, 33, 477.

(1952). Trans. ophthal. Soc. U.K., 72, 613.

(1955). Ibid., 75, 629.

WhitTINGHAM, T. H. (1952). Ibid., 72, 395. 